\title{
Prediction of the stress-strain state of circular workings in a layered massif by scaling
}

\author{
Ahmad Alkhdour ${ }^{1}$, Anatolii Radkevych $^{2}$, Oleksii Tiutkin ${ }^{2, *}$, and Nataliia Bondarenko $^{2}$ \\ ${ }^{1}$ Al-Balqa` Applied University, 19117, Al-Salt, Jordan \\ ${ }^{2}$ Dnipro National University of Railway Transport named after Academician V. Lazaryan, 49010, \\ Dnipro, Lazaryan Str., 2, Ukraine
}

\begin{abstract}
The scientific and technical task for determining the stress-strain state of mine workings is complicated by the presence of a layered massif. This task assumes particular importance in the case of circular tunneling. During its operation, it is important to predict the change of the stressstrain state for the massif or to carry out the prompt determination in the change of stresses and displacements for the unsupported working. The solution of this geomechanical task allows performing geometrical matching of the working, ensuring its strength and stability in the layered massif. A numerical finite element method based on StructureCAD (SCAD) software package was used to solve it. Four geomechanical systems were calculated: "unsupported working - layered massif". Owing to the obtained results, graphs of stresses and displacements were constructed, which allow to determine these parameters for workings with different geometric parameters and $\chi$-parameter characterizing the ratio of the elasticity modulus of the matrix and the layer. Obtained regularities of change of stresses and displacements for the unsupported working when zooming made it possible to introduce scaling-parameters, which are a dimensionless ratio of the radii for a real system and a system with a unit diameter.
\end{abstract}

\section{Introduction}

The usage of shield tunneling while constructing the metro running tunnels or the opening of large-diameter workings in parts requires a clear knowledge of the stress-strain state for the massif surrounding the working [1]. This task is related to the second, no less important geomechanical task, which is to define the strength and stability of the unsupported working. For shield tunneling, this second task is not the main one, which is explained by the peculiarities of the rock development process, during which the shield shell supports the rock massif. But for the case of the opening of large-diameter workings in parts, for example, a side tunnel of a pylon or columnar type station, a normal construction process can be ensured only by solving this linked task, in which the determination of both stress and strain states is not subject to hierarchy, since ensuring the strength and stability of the working until the installation of temporary or permanent fastening can not be divided.

\footnotetext{
*Corresponding author: alexeytutkin@gmail.com
} 
However, the problem of stability while ensuring the strength of the surrounding massif when shield tunneling does not disappear. It is transformed into a problem of ensuring the geometric position of the rim rings according to the project. The construction experience of the Kyiv metro in weak layered soils indicates that installation of the ring into the specified position is a rather difficult task, which was noted in papers $[1,2]$. While fully ensuring the global stability of the working, supported by the cylindrical design of the shield, its local impact on the weak rocks of the surrounding massif results in a permanent change of the tunnel axis in the profile. Therefore, the research of stability, in this case, is important and relevant.

The solution of this linked geomechanical task in determining the stress-strain state is complicated by the presence of one or more layers that have different strength and deformation characteristics. Analytical solutions to this problem are few in number and most often can be used only in some specific cases [3-7]. Other solutions based on the application of numerical methods are specific $[8,9]$ and do not have any generalization $[10,11]$.

In addition to the analyzed features in ensuring the strength and stability of shield tunneling while constructing the metro running tunnels or the opening of the large-diameter workings in parts, one more important fact should be noted. An urgent issue of these methods in the construction of underground objects is a prediction of the change of the stress-strain state in case of a change in the characteristics of the layer: its thickness, change of position in the surrounding massif, deformation characteristics, etc. [12]. This issue has hardly been addressed on the basis of an analytical approach, it is explained by an objective reason, namely the significant complexity of taking into account the above characteristics $[3,5,6]$. The numerical analysis of such situations in changing the characteristics of the layer is also not simple, since it requires, besides the basic ones, a significant range of additional calculations.

Thus, there is an actual geomechanical task, the solution of which will allow, first of all, to perform the selection of geometric parameters of the working, ensuring its strength and stability in the layered massif, and, secondly, to perform express analysis [12] of changes in the stress-strain state of the unsupported working in the layered massif that changes its own geometric and deformation characteristics.

\section{Methods}

The solution of this urgent task is possible only with the help of numerical methods, for example, the finite element method, and with its implementation in powerful professional computational complexes [10-13]. However, even the presence of such a complex does not exclude the need for multiple calculations of each individual case in a change of the stressstrain state of the unsupported working in the layered massif. Therefore, the authors of this research propose a methodological technique, which has already been widely tested by representatives of the so-called Tula School. But the main difference is that this analytical approach was applied in the course of numerical analysis, that is, it was rethought in the framework of mathematical simulation based on the finite element method.

In papers $[5,6]$ for workings of various configurations, the equation for the contour which is written in a complex form, is presented:

$$
z=x+i y=R\left(\xi+\frac{C_{1}}{\xi^{n}}+\frac{C_{2}}{\xi^{m}}\right),
$$

where $R$ - a scale parameter that determines sizes of the contour; $C_{1}, C_{2}, n, m-$ 
parameters that determine the configuration and shape of the contour; $\Theta$ - polar angle; $\xi=\rho e^{i \Theta}, \rho=1 ; i=\sqrt{-1}$.

This formula at $\rho \geq 1$ is an analytical function $z=\omega(\xi)$, that conformally displays the view of a unit circle with radius $\rho=1$ to the view of the specified geometric contours.

The initial stress state of the rock mass is hydrostatic (pressure ratio $\lambda=1$ ), in this case, the initial stresses are determined by analytical functions

$$
\phi(\xi)=\frac{1}{2} R \gamma H \xi, \psi(\xi)=0
$$

and additional and total stresses - by functions in the form:

$$
\phi(\xi)=-\frac{1}{2} R \gamma H \frac{C_{1}}{\xi^{n}}, \psi(\xi)=R \gamma H \frac{\xi^{n}\left(1+n C_{1}^{2}\right)}{n C_{1}-\xi^{n+1}} .
$$

The stress components $\sigma_{\Theta}, \sigma_{\rho}$ and $\tau_{\Theta \rho}$ in the curvilinear orthogonal coordinate system $\rho-\Theta$, which is provided by conformal mapping (1), are found by the KolosovMuskhelishvili formulas:

$$
\begin{gathered}
\sigma_{\rho}+\sigma_{\Theta}=4 R \Phi(\xi) \\
\sigma_{\Theta}-\sigma_{\rho}+2 i \tau_{\rho \Theta}=\frac{2 \xi^{2}}{\rho^{2} \omega(\xi)}\left[\omega(\xi) \Phi^{\prime}(\xi)+\psi^{\prime}(\xi)\right] \\
\Phi(\xi)=\frac{\phi^{\prime}(\xi)}{\psi^{\prime}(\xi)} .
\end{gathered}
$$

Having substituted values (2) and (3) in (4), and then summed them up and accepted $\rho=1, \sigma_{\rho}=0$, we obtain a formula for the distribution of total stresses $\sigma_{\Theta}$ on the contour along the sites, normal to the working:

$$
\sigma_{\Theta}=2 \gamma H \frac{1-n^{2} C_{1}^{2}}{1+n^{2} C_{1}^{2}-2 n C_{1} \cos (n+1) \Theta} .
$$

Obviously, these functions are used to research the stress-strain state of a homogeneous isotropic massif around horizontal workings. Their application in the case of layered massifs is problematic because of the complex mathematical apparatus. However, the methodological technique itself is very fruitful. It is possible to obtain a solution for the stress-strain state at the working with a unit radius without using complex direct and inverse conformal mappings by applying scaling, that is, scaling the stress-strain state when changing the radius of the working [14].

The important point when we apply scaling is that it is completely correct when it is applied to layered massifs. To predict changes in stress-strain state, two finite-element models of the unsupported working occurring in the layered massif were developed, and the power of the layer in each of them is changed according to the radius of the working (Fig 1).

In the finite element models in order to reproduce the spectrum of deformation characteristics of the matrix (surrounding massif) and the layer, $\chi$-parameter is used, which 
characterizes the ratio of the elasticity modulus of the matrix and the layer [11]:

$$
\chi=\frac{E_{m}}{E_{s}},
$$

where $E_{m}$ - elasticity modulus of the matrix; $E_{s}$ - elasticity modulus of the layer.

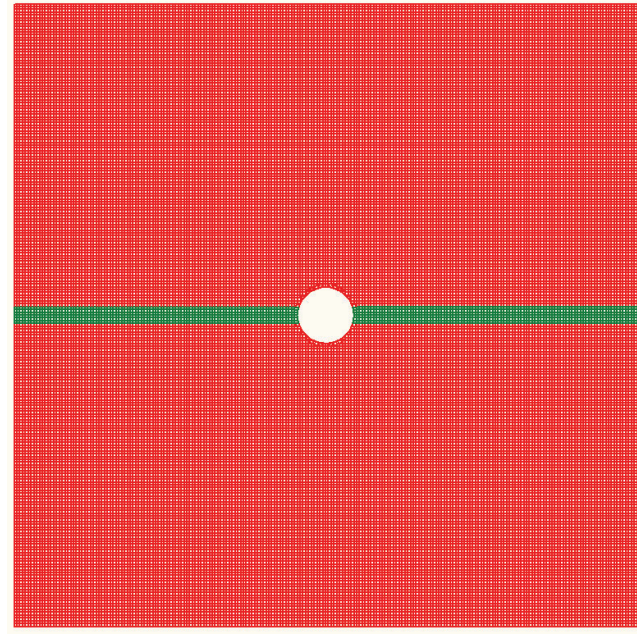

1)

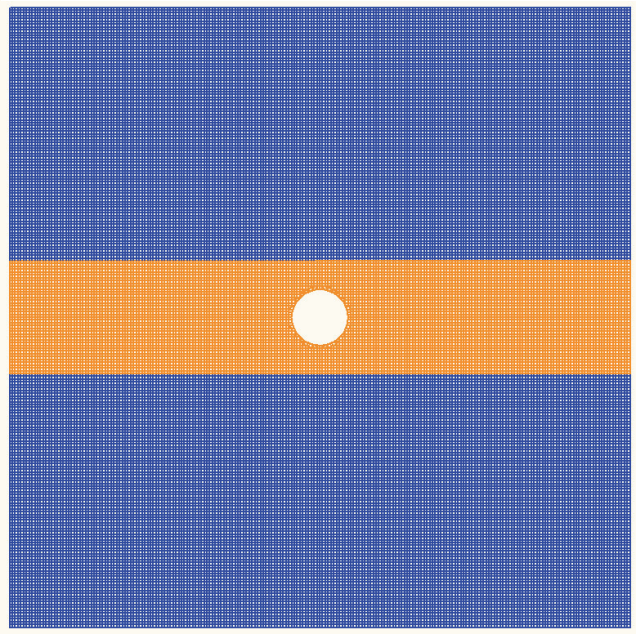

2)

Fig. 1. Finite element models of the unsupported working with radius $R$, occurring in the layered massif: 1) layer thickness is of $0.5 R ; 2$ ) layer thickness is of $4 R$.

A rock massif is simulated in the finite element model, discretized to finite elements by automatic triangulation (with the merger of triangular elements into rectangular ones), the type of elements of a flat stress problem is applied, which allows simulating the work of the surrounding layered massif. The basic equation of the finite element method in SCAD (license number F755B84 (KMBKB RA 4810)) is solved based on the elastic solution.

\section{Results and discussion}

After the model had been created, its full calculation with the matrix expansion by the multifrontal method was performed. Figure 2 shows the characteristic isolines and isofields of the analyzed stresses for the contour of unsupported working occurring in a layered massif with the same $\chi$-parameter values and different layer thicknesses that were analyzed. Since a lot of illustrative material has been obtained, only the most characteristic data are presented that undoubtedly prove the provisions of this paper.

The analysis of the results array allows us to state that in order to obtain stresses and displacements of unsupported workings with a real radius is sufficient while scaling to increase the stress by factor of $n$, and displacement by factor of $n^{2}$ for the system with a unit geometric parameter. Scaling-parameter $n$ is the dimensionless ratio of the radii of a real system and a system with a unit geometric parameter. Thus, it is sufficient to calculate only one case of layering with a defined layer thickness and $\chi$-parameter, so that, by using scaling-parameters, one can determine the stress-strain state of workings of other geometric parameters. Accordingly, based on the obtained results, it is possible to predict the stressstrain state of circular workings in the layered massif. 


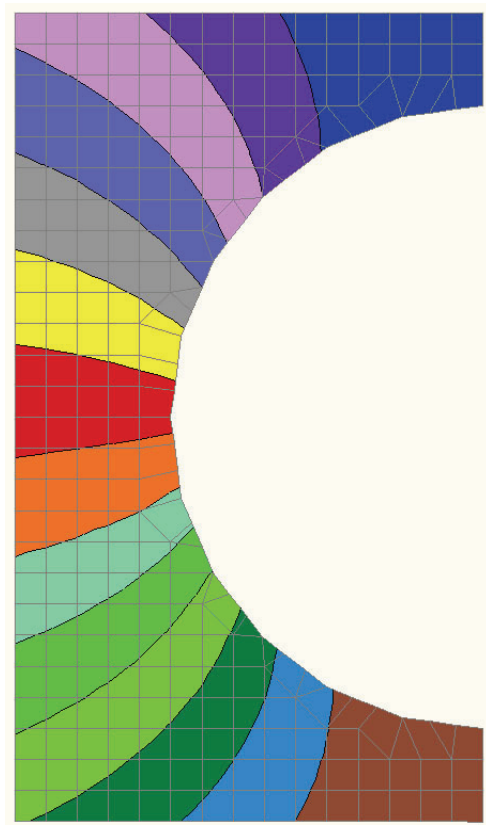

1)

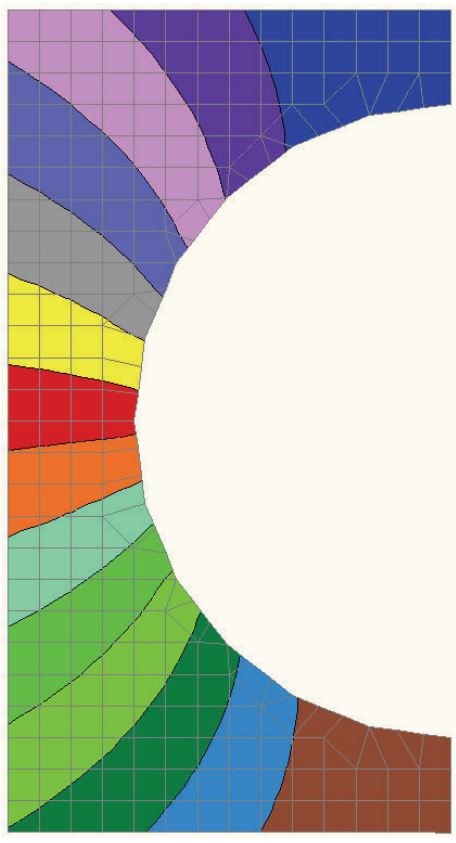

3)

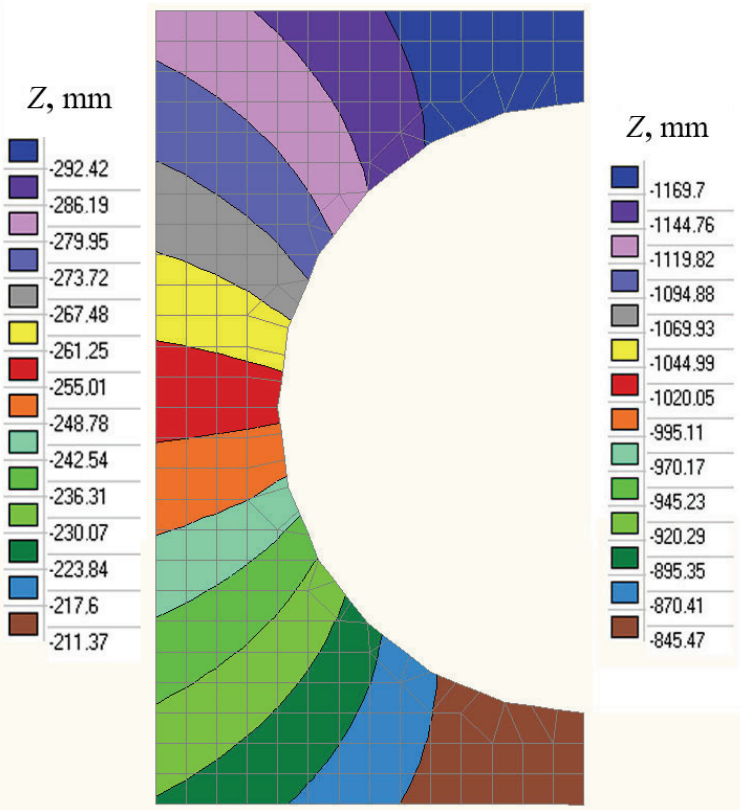

2)

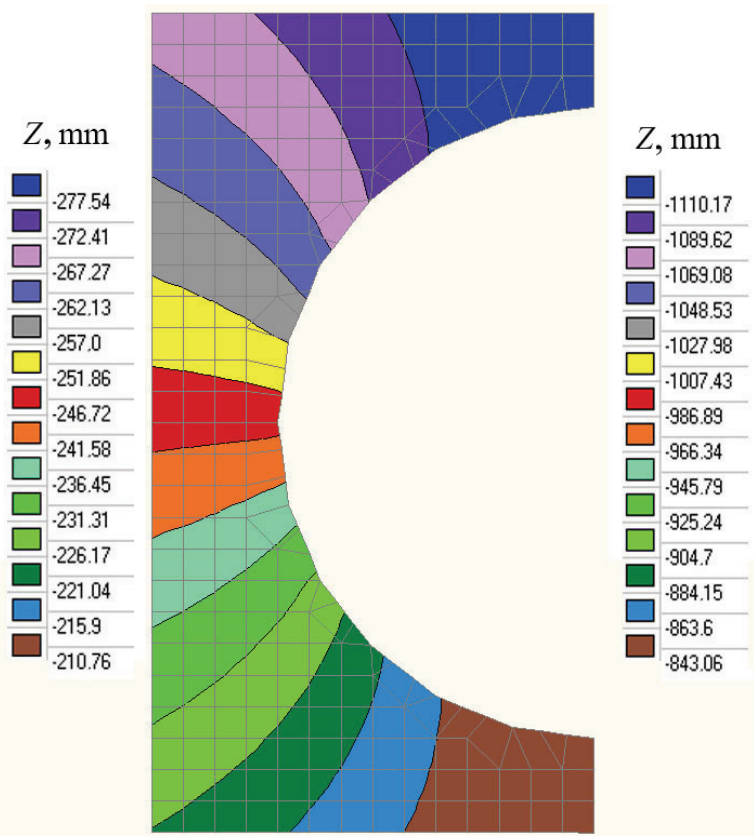

4)

Fig. 2. Characteristic isolines and isopoles of vertical displacements $Z$, for the contour of the unsupported working $R=1$ occurring in a layered massif $\left(\chi=2, E_{\mathrm{m}}=30 \mathrm{MPa}, E_{\mathrm{s}}=15 \mathrm{MPa}\right)$ : 1) layer thickness is of $0.5 R$ (working diameter is of $1 \mathrm{~m}$ ); 2) layer thickness is of $0.5 R$ (working diameter is of $2 \mathrm{~m}$ ); 3) layer thickness is of $4 R$ (working diameter is of $1 \mathrm{~m}$ ); 4) layer thickness is of $4 R$ (working diameter is of $1 \mathrm{~m}$ ). 


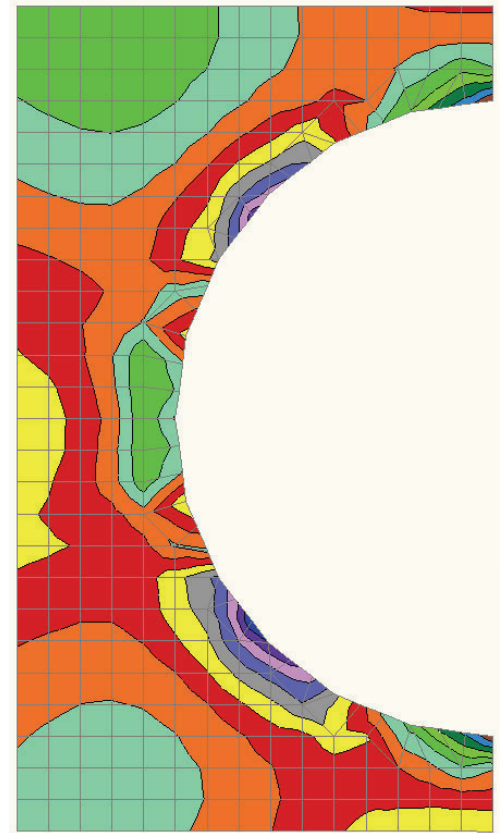

1)

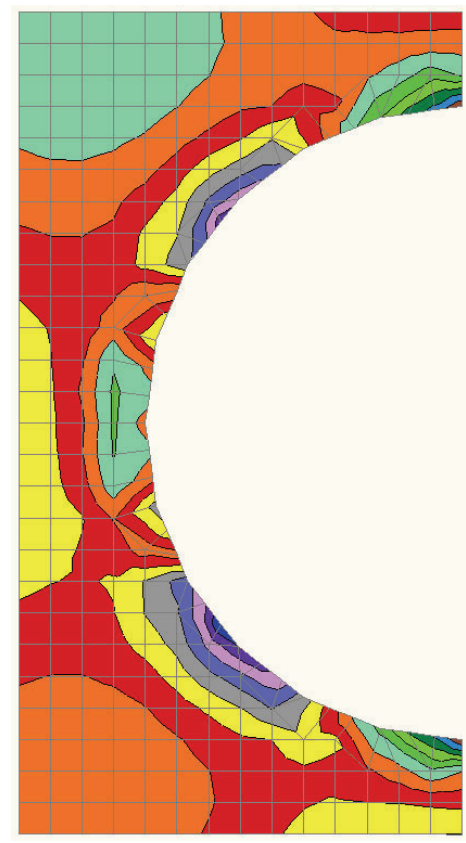

3)

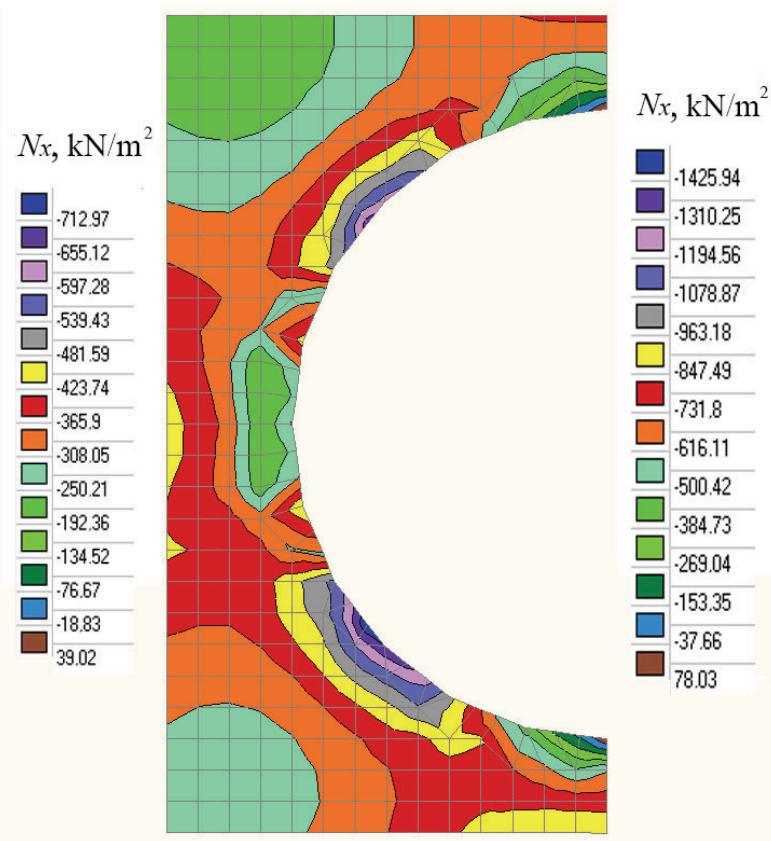

2)

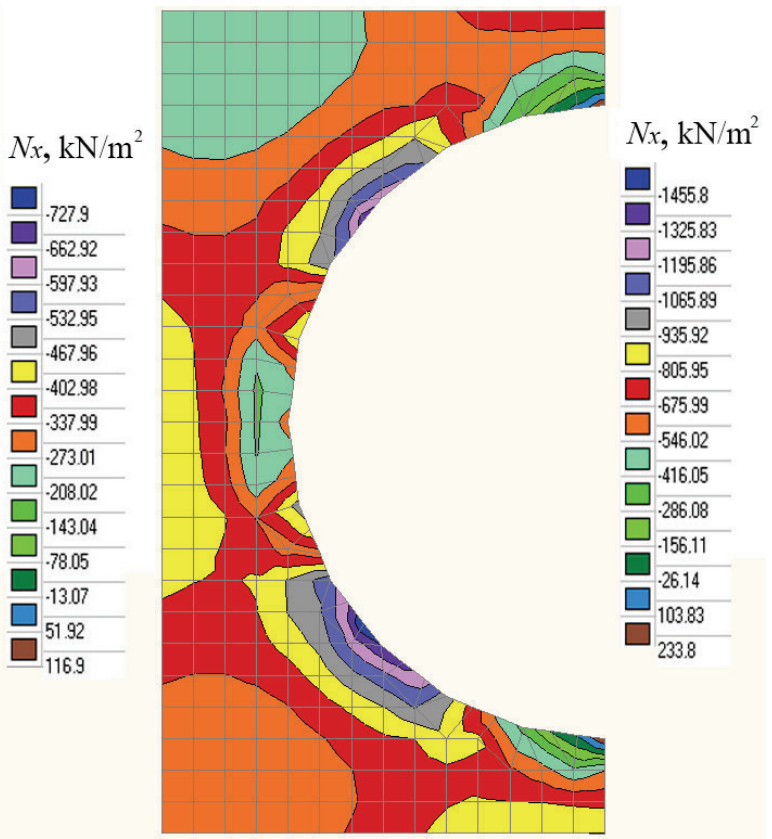

4)

Fig. 3. Characteristic isolines and isofields of normal stresses $N_{x}$ along the horizontal axis of the contour of the unsupported working $R=1$, occurring in a layered massif ( $\chi=2, E_{\mathrm{m}}=30 \mathrm{MPa}$, $E_{\mathrm{s}}=15 \mathrm{MPa}$ ): 1) layer thickness is of $0.5 R$ (working diameter is of $1 \mathrm{~m}$ ); 2) layer thickness is of $0.5 R$ (working diameter is of $2 \mathrm{~m}$ ); 3) layer thickness is of $4 R$ (working diameter is of $1 \mathrm{~m}$ ); 4) layer thickness is of $4 R$ (working diameter is of $1 \mathrm{~m}$ ). 
In order to make the prediction process more detailed, the results array was analyzed in the course of the numerical analysis, and to further define the regularities of the stress state there were selected five characteristic points of the working contour, in which the values of the stress components were determined (Fig. 4).

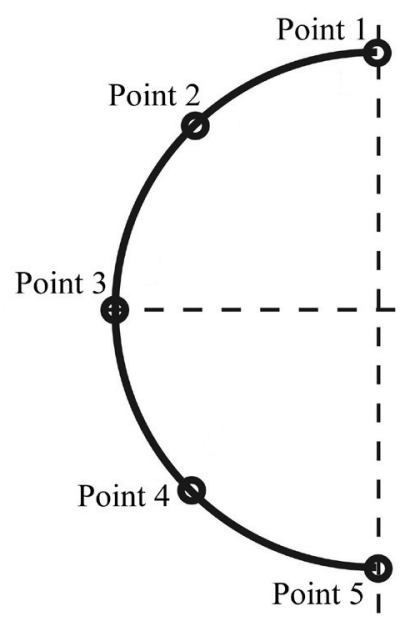

Fig. 4. Scheme of characteristic points on the contour of the unsupported working occurring in the layered massif, in which three components of stresses are defined.

On the basis of the obtained results for the characteristic points, authors constructed graphs of the regularities of displacements and stresses for the contour of the unsupported working occurring in the layered massif from $\chi$-parameter (Fig. 5-12) [11].

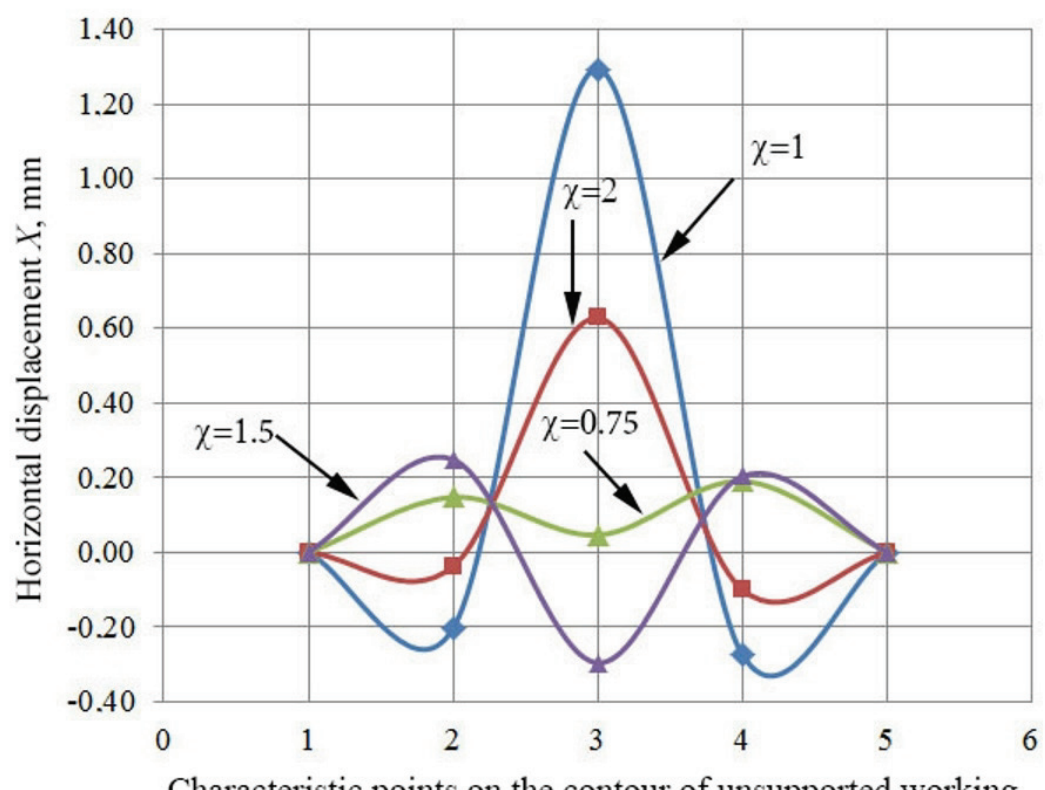

Characteristic points on the contour of unsupported working

Fig. 5. Horizontal displacements at characteristic points of the working with the unit diameter at different values of $\chi$-parameter and layer thickness of $0.5 R$. 


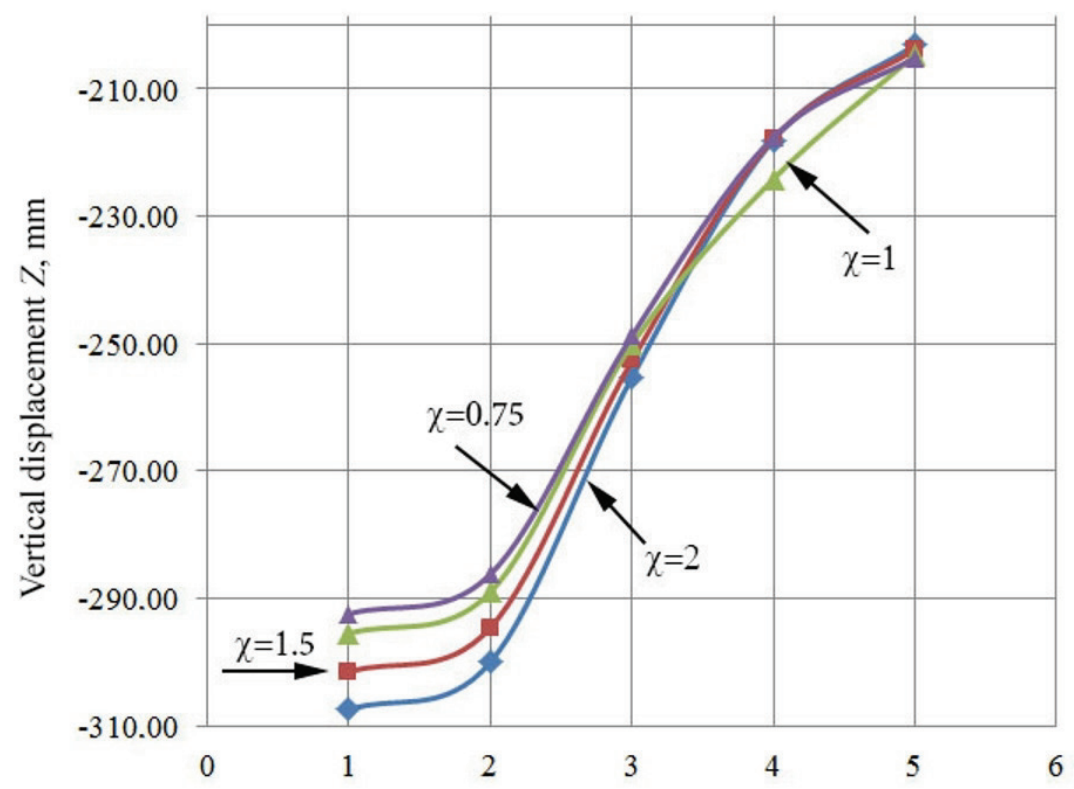

Characteristic points on the contour of unsupported working

Fig. 6. Vertical displacements $(\mathrm{mm})$ at characteristic points of the working with the unit diameter at different values of $\chi$-parameter and layer thickness of $0.5 R$.

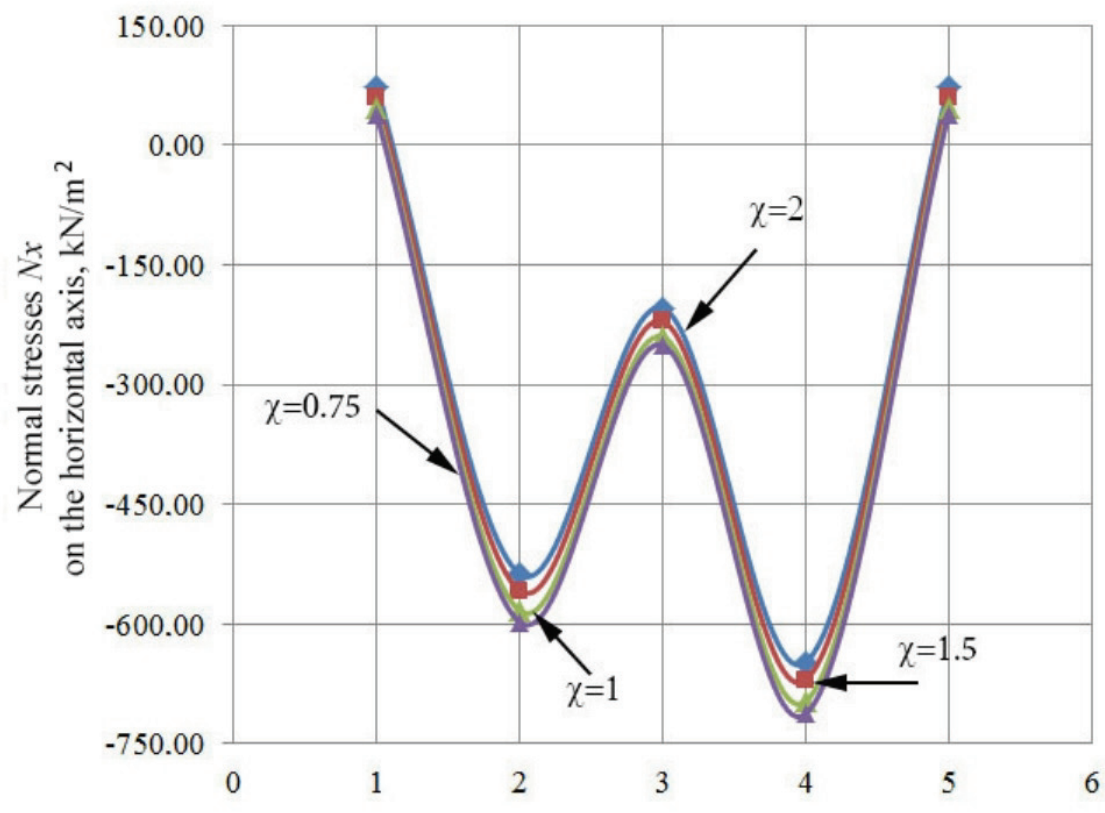

Characteristic points on the contour of unsupported working

Fig. 7. Normal stresses on the horizontal axis at characteristic points of the working with the unit diameter at different values of $\chi$-parameter and layer thickness of $0.5 R$. 


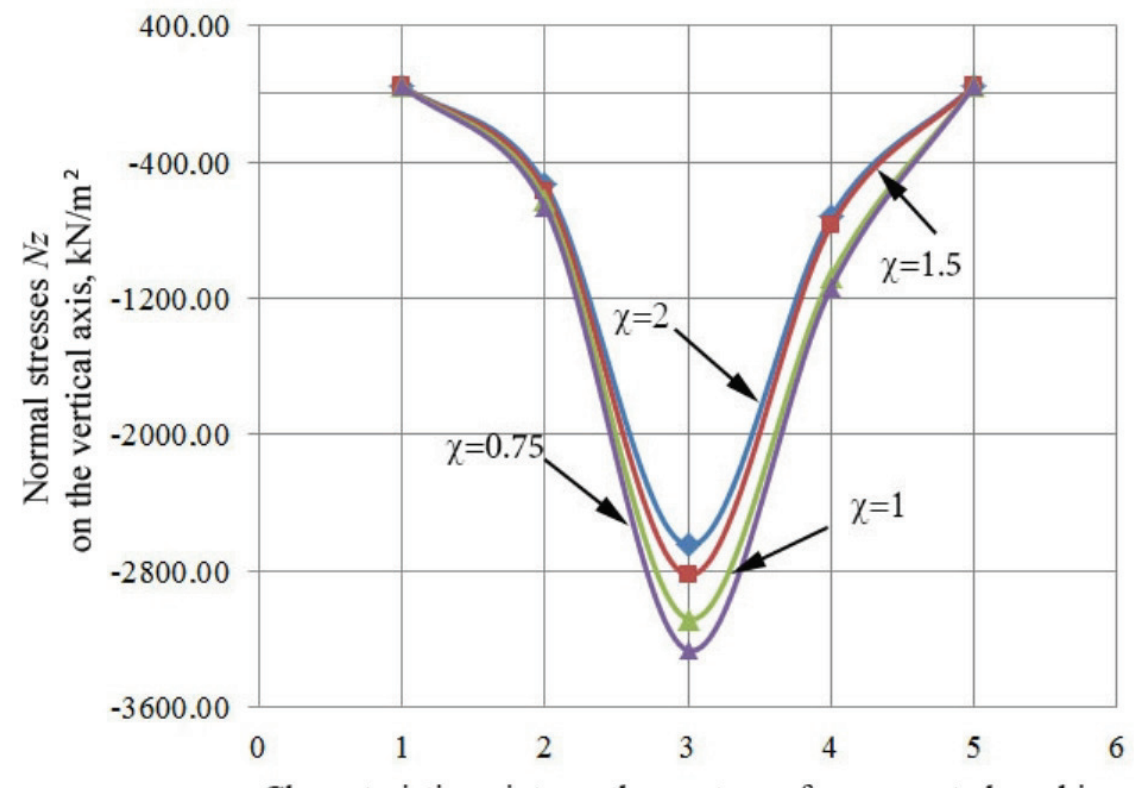

Characteristic points on the contour of unsupported working

Fig. 8. Normal stresses on the vertical axis at characteristic points of the working with the unit diameter at different values of $\chi$-parameter and layer thickness of $0.5 R$.

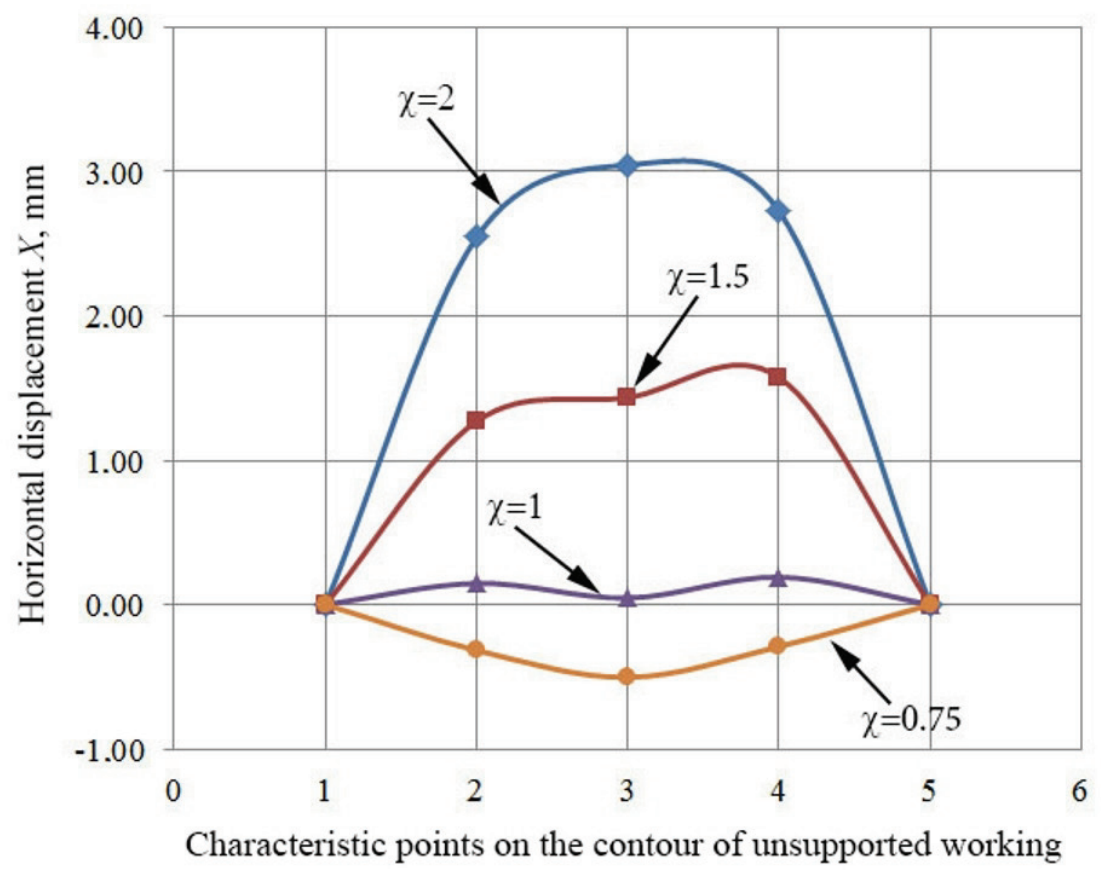

Fig. 9. Horizontal displacements at characteristic points of the working with the unit diameter at different values of $\chi$-parameter and layer thickness of $4 R$. 


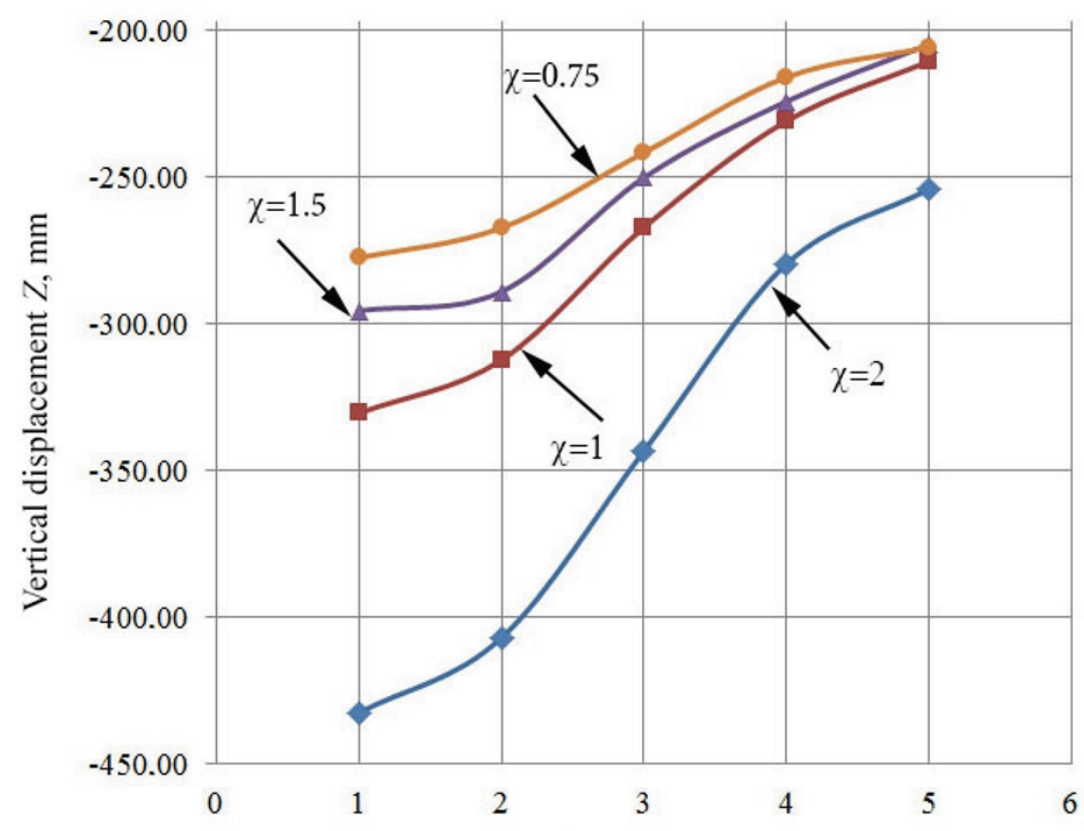

Characteristic points on the contour of unsupported working

Fig. 10. Vertical displacements at characteristic points of the working with the unit diameter at different values of $\chi$-parameter and layer thickness of $4 R$.

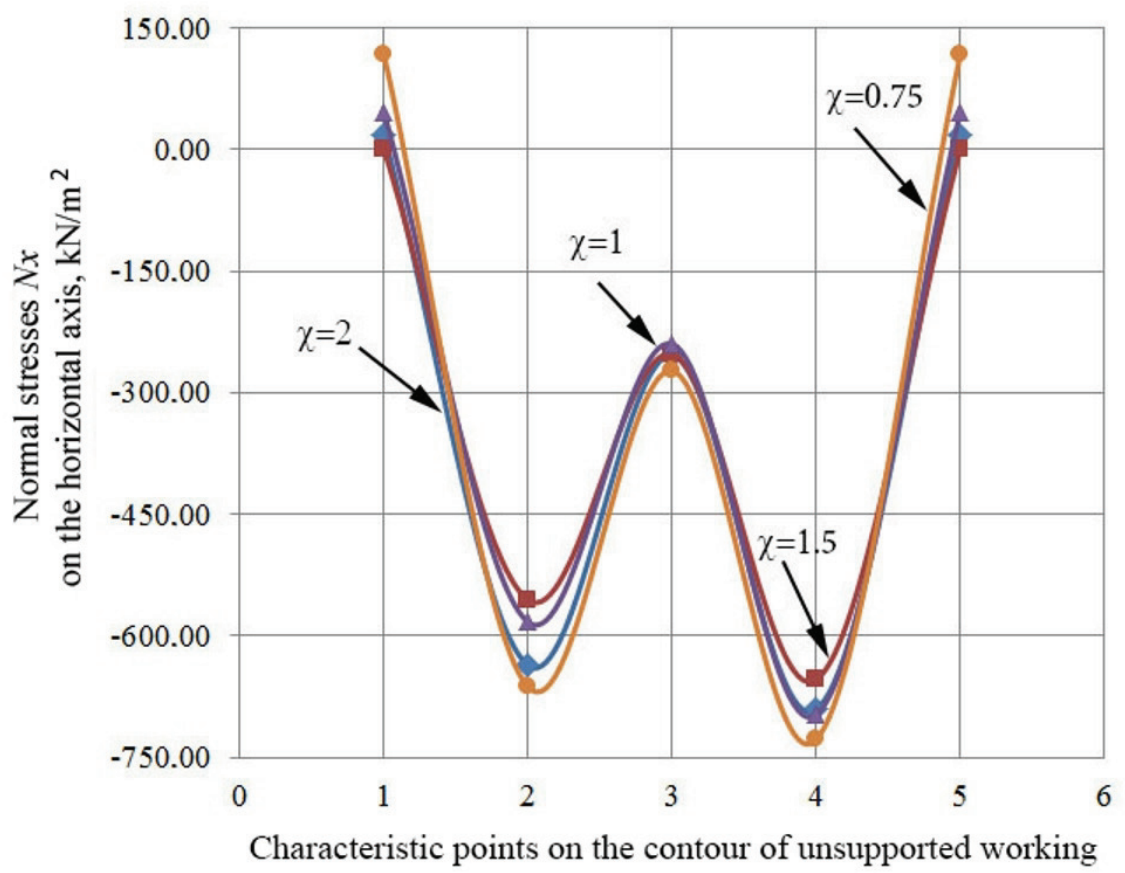

Fig. 11. Normal stresses on the horizontal axis at characteristic points of the working with the unit diameter at different values of $\chi$-parameter and layer thickness of $4 R$. 


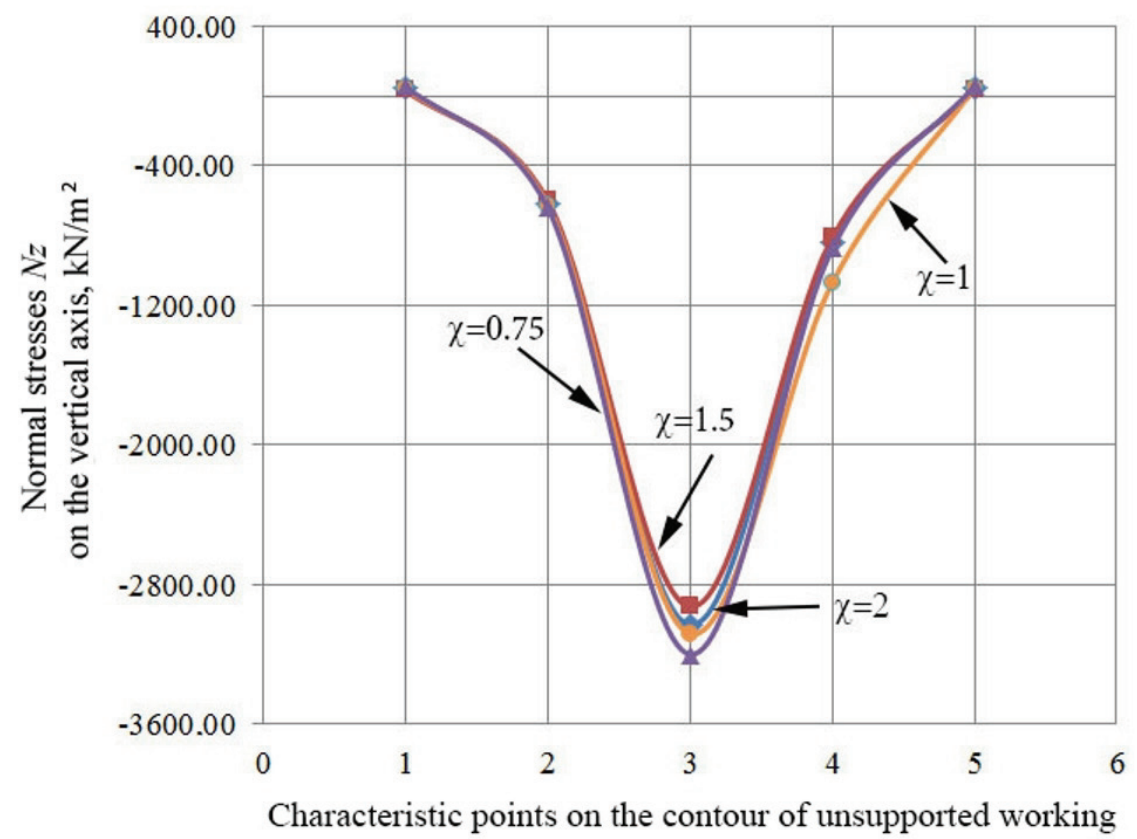

Fig. 12. Normal stresses on the vertical axis at characteristic points of the working with the unit diameter at different values of $\chi$-parameter with the layer thickness of $4 R$.

The presented figures do not show the parameters of the stress-strain state at the thickness of the layer within $0.5 R \ldots 4 R$. However, it is enough to calculate one specific option of the working, while applying scaling-parameters, to determine the stress-strain state for workings of the second diameter. Practically, this consists in the fact that values in the presented graphs can be multiplied by the scaling-parameters (to increase stress by factor of $n$, and displacements by factor of $n^{2}$ ), since the calculated working has a unit diameter.

\section{Conclusions}

Obtained regularities of displacements and stresses for the contour of the unsupported working, occurring in the layered massif, at different values of the $\chi$-parameter make it possible to predict the change in the stress-strain state of workings of all diameters different from the unit. This allows in practical calculations at different values of $\chi$-parameter and radius $R$, using scaling-parameters (to increase stress by factor of $n$, and displacements by factor of $n^{2}$ ) without additional actions to calculate displacements and stresses at five characteristic points of the working, only having defined the ratio between the deformation properties of the matrix and the layer and the ratio between parameters.

The defined regularities allow to predict the stress-strain state of circular workings in the layered massif by means of scaling. In practical terms, this opens the possibility to analyze the situation with the variation of parameters, which is on the front burner for tunneling of mine workings in a layered massif. Prompt analysis of displacements and stresses can allow even at the stage of design and analysis of the engineering-geological situation to draw up a rational plan and rout profile, which are characterized by the most favorable stress-strain state. Such prediction makes it possible to maximally use the initial 
information and solve the task of the strength and stability of workings that occurring in the layered massif.

\section{References}

1. Petrenko, V.D., Tiutkin, A.L., Petrenko, V.I. (2007). Sravnitelnyy analiz rezultatov naturnykh issledovaniy i matematicheskogo modelirovaniya peregonnogo tonnelya mezhdu stantsiyami "Lybedskaya"-"Demeyevskaya", Heotekhnichna mekhanika, 73, 91-100

2. Tiutkin, O.L., Petrenko, V.D., Huzchenko, V.T., Tiutkin, D.V. (2014). Analysis of deformed state structures of the Kyiv metro running tunnels on a transition zone from spondylov's clay to buchatskiy sands, Science and Transport Progress, 4(52), 127-138

3. Savin, G.N. (1968). Raspredeleniye napryazheniy okolo otverstiy. Kiyev: Naukova dumka

4. Zhukov, V.V., Chernov, E.V., Dovgenko, T.N. (1973). Napryazhennodeformirovannoye sostoyaniye sloistogo massiva. Leningrad: Nauka

5. Baklashov, I.V., Kartoziya, B.A. (1984). Mekhanika podzemnykh sooruzheniy $i$ konstruktsii krepey. Moskva: Nedra

6. Bulychev, N.S. (1994). Mekhanika podzemnykh sooruzheniy. Moskva: Nedra

7. Kravchenko, T.I., Filatov, V.V., Kim, B.G., Dubov, K.A. (2016). Raschet odnosloynykh $i$ mnogosloynykh gruntovykh sred ot deystviya vneshnikh nagruzok $v$ lineynoy postanovke zadach (uchebnoye posobiye). Vladimir: Izd-vo VlGU

8. O. Voloshyn, O. Riabtsev. Some important aspects of rock mechanics and geomechanics. E3S Web of Conferences, International Conference Essays of Mining Science and Practice, 109 (2019). https://doi.org/10.1051/e3sconf/201910900114

9. O. Riabtsev, S. Protsak. Approbation of the theory of fractals and damageability of rocks when solving geomechanical problems. E3S Web of Conferences, International Conference Essays of Mining Science and Practice, 109 (2019). https://doi.org/10.1051/e3sconf/201910900079

10. S. Monti Commun. Sci. Lett. Univ. Zilina 20, 3 (2018)

11. S.K. Dhir J. Appl. Mech., 484 (1981)

12. Petrosian, N.K., Tiutkin, A.L. (2017). Ekspress-analiz napryazhennodeformirovannogo sostoyaniya nezakreplennoy vyrabotki na osnove modeli $\mathrm{s}$ edinichnymi parametrami, Bridges and tunnels: Theory, Research, Practice, 11, 60-66

13. O. Tiutkin, N. Petrosian, A. Radkevych A. Alkhdour. Regularities of stress state of unsupported working occurring in a layered massif. E3S Web of Conferences, International Conference Essays of Mining Science and Practice, 109 (2019). https://doi.org/10.1051/e3sconf/201910900100

14. Bondarenko, N.K., Tiutkin, O.L. (2019). Zakonomirnosti napruzheno-deformovanoho stanu nezakriplenoi vyrobky yak funktsii scaling-parametriv. In: Transportni sporudi: stan, problemi zberezhennya, remont, $48-50$ 